\title{
Antioxidant Activity of Flavonoid from Rhizome Kaemferia galanga L. Extract
}

\author{
Elok Kamilah Hayati, Rachmawati Ningsih, Latifah \\ Jurusan Kimia Fakultas Sains dan Teknologi Universitas Islam Negeri Maulana Malik Ibrahim Malang \\ Email: eloksunardji@yahoo.com
}

\begin{abstract}
Kaemferia galanga $\mathrm{L}$. rhizome is a traditional crop which is widely used for herbal medicine. This research is started from the extraction of maceration using ethanol $80 \%$ and partition with chloroform:water. $80 \%$ ethanol extract and chloroform fraction tested antioxidant activity with DPPH (1,1-diphenyl-2-picrylhydrazyl), phytochemicals with reagents, separation of the active compound by TLC (thin layer chromatography) analytical and preparative TLC, the identification of compounds with sliding reagent using UV-Vis. The test results on the antioxidant activity of $80 \%$ ethanol extract of $64,93 \%(100 \mathrm{ppm})$ and chloroform fraction of 54,9 $\%$ (100 ppm) with indigo IC50 of 13,07 mg/mL and 81,9 mg mL. $80 \%$ ethanol extract and chloroform fraction has potential as a source of natural antioxidants. Phytochemical test showed $80 \%$ ethanol extract contains flavonoids, alkaloids and tannins. At the chloroform fraction extract containing flavonoids. The separation of the active compounds with analytical TLC using eluent PE: ethyl acetate (5:1) resulted in 7 stain (Rf 0,06 to 0,96$)$ and preparative TLC produce 8 spots (Rf from 0,19 to 0,83 ). Results from UV-Vis spectrum can be presumed that such a class of flavonoid compounds flavanones or dihidroflavonol. It can be seen from the wavelength range $210-285 \mathrm{~nm}$ in the bands I and $300-550 \mathrm{~nm}$ in band II. The addition of the reagent slide showed the presence of hydroxyl groups in ring $\mathrm{A}, \mathrm{B}$ and $\mathrm{C}$ and O-hydroxy on ring $\mathrm{A}$.
\end{abstract}

Keywords: antioxidant activity, Kaemferia galanga rizhome, sliding reagent, Thin Layer Chromatography, 1,1diphenyl-2-picrylhydrazyl

\begin{abstract}
Abstrak
Kencur merupakan tanaman tradisional yang banyak dimanfaatkan sebagai obat alami. Penelitian ini diawali dengan ekstraksi maserasi menggunakan pelarut etanol $80 \%$ dan partisi dengan kloroform:air. Ekstrak etanol $80 \%$ dan fraksi kloroform dilakukan uji aktivitas antioksidan dengan DPPH, fitokimia dengan reagen, pemisahan senyawa aktif dengan KLT analitik dan KLT preparatif, identifikasi senyawa dengan pereaksi geser menggunakan UV-Vis. Hasil uji aktivitas antioksidan pada ekstrak etanol $80 \%$ sebesar 64,93\% (100 ppm) dan fraksi kloroform 54,9\% (100 ppm) dengan nila $\mathrm{IC}_{50}$ sebesar $13,07 \mathrm{mg} / \mathrm{mL}$ dan $81,9 \mathrm{mg} / \mathrm{mL}$. Ekstrak etanol $80 \%$ dan fraksi kloroform mempunyai potensi sebagai sumber antioksidan alami. Uji fitokimia menunjukkan ekstrak etanol $80 \%$ mengandung senyawa flavonoid, alkaloid dan tanin. Pada ekstrak fraksi kloroform mengandung senyawa flavonoid. Pemisahan senyawa aktif dengan KLT analitik menggunakan eluen PE:etil asetat (5:1) menghasilkan 7 noda (Rf 0,06-0,96) dan KLT preparatif menghasilkan 8 noda (Rf 0,19-0,83). Hasil dari spektrum UV-Vis dapat diduga bahwa senyawa flavonoid tersebut merupakan golongan flavanon atau dihidroflavonol. Hal ini dapat dilihat dari rentang panjang gelombang 210 - $285 \mathrm{~nm}$ pada pita I dan $300-550 \mathrm{~nm}$ pada pita II. Penambahan pereaksi geser menujukkan adanya gugus hidroksi pada cincin A, B dan C dan $\mathrm{O}-$ hidroksi pada cincin A.
\end{abstract}

Kata kunci: aktivitas antioksidan, Kaemferia galanga L., pereaksi geser, kromatografi lapis tipis, 1,1-diphenyl-2picrylhydrazyl

\section{Pendahuluan}

Indonesia dikenal dengan kekayaan sumber daya alamnya yang melimpah, salah satunya yaitu memiliki aneka ragam tumbuhan yang digunakan sebagai obat tradisional. Salah satu tumbuhan yang memiliki potensi sebagai obat yaitu rimpang kencur (Kaemferia galanga L) Wijayakusuma, 2008). Rimpang kencur sudah dikenal luas di masyarakat baik sebagai bumbu makanan atau untuk pengobatan diantaranya adalah batuk, mual, 
bengkak, bisul dan antitoksin seperti keracunan tempe bongkrek dan jamur. Selain itu, berkhasiat untuk menambah daya tahan tubuh, menghilangkan masuk angin, dan kelelahan (Gholib, 2009).

Rimpang kencur mengandung beberapa senyawa aktif. Hasil penelitian Hasanah (2011) menginformasikan bahwa hasil skrining fitokimia ekstrak etanol rimpang kencur terdeteksi mengandung senyawa flavonoid, polifenol, tanin, kuinon, dan seskuiterpen.

Flavonoid merupakan salah satu kelompok senyawa metabolit sekunder yang paling banyak ditemukan di dalam jaringan tanaman. Flavonoid berperan sebagai antioksidan dengan cara mendonasikan atom hidrogennya atau melalui kemampuannya mengkelat logam, berada dalam bentuk glukosida (mengandung rantai samping glukosa) atau dalam bentuk bebas yang disebut aglikon (Cuppett, 1954).

Metode yang sering digunakan dalam pengujian antioksidan adalah DPPH yang merupakan radikal bebas yang stabil. Parameter yang digunakan untuk mengetahui aktivitas antioksidan ialah $\mathrm{IC}_{50}$ (konsentrasi substrat untuk menghasilkan $50 \%$ reduksi dari DPPH) (Molyneux, 2003).

Eluen-eluen yang digunakan untuk memisahkan senyawa flavonoid adalah metanol-kloroform (1:39) dan (1:9) (Milyasari, 2011) menghasilkan bercak lembayung gelap, petroleum eter-etil asetat (5:1) menghasilkan bercak coklat-merah dan kloroform-metanol-air $\quad(9,7: 0,2: 0,1)$ (Fitriani, 2011).

Penelitian ini dilakukan untuk mengetahui aktivitas antioksidan dan dugaan senyawa flavonoid yang terdapat pada ekstrak rimpang kencur. Hasil penelitian ini diharapkan dapat memberikan informasi ilmiah dan sebagai studi pendahuluan potensi senyawa flavonoid yang terkandung dalam kencur Kaemferia galanga $L$.

\section{Metodologi Penelitian}

Bahan yang digunakan pada penelitian ini terdiri dari serbuk rimpang kencur yang berasal dari Materia Medika Batu. Bahan kimia etanol p.a, $\mathrm{HCl} 2 \%$, kloroform, $\mathrm{NaOH}$, asam asetat glasial, petroleum eter, n-butanol, aquades, $\mathrm{H}_{2} \mathrm{SO}_{4}$, larutan $\mathrm{FeCl}_{3}$, reagen Dragendrofff, reagen Meyer, pereaksi Lieberman Burchard, DPPH, vitamin $\mathrm{C}$, logam $\mathrm{Mg}$, asam asetat anhidrat, amonia dan plat KLT Gel $60 \mathrm{~F}_{254}$. Peralatan yang digunakan dalam penelitian ini adalah spektronik 20+ dan UV-vis.

\subsection{Preparasi sampel}

Sampel rimpang kencur dicuci hingga bersih, lalu dikering anginkan kemudian sampel dipotong kecil-kecil. Setelah itu, sampel kering dihaluskan dengan blender hingga halus dan diayak dengan ayakan 90 mesh.

\subsection{Ekstraksi maserasi}

Serbuk rimpang kencur ditimbang sebanyak 60 gram. Kemudian dilarutkan dengan pelarut etanol $80 \%$ sebanyak $180 \mathrm{~mL}$. Maserasi dilakukan selama 24 jam, kemudian dishaker selama 3 jam dengan kecepatan $120 \mathrm{rpm}$, kemudian disaring dan ampas yang diperoleh dimaserasi kembali dengan pelarut yang sama dan dilakukan sebanyak 3 kali pengulangan sampai filtratnya berwarna bening. Selanjutnya disaring dan filtratnya dipekatkan menggunakan rotary evaporator vaccum.

Ekstrak pekat sebanyak 2,5 gram yang diperoleh selanjutnya dihidrolisis dengan $\mathrm{HCl} 2 \mathrm{~N}$ sebanyak $5 \mathrm{~mL}$ kemudian dihomogenkan selama 1 jam, lalu dipartisi dengan pelarut air : kloroform (1:1) sehingga terbentuk 2 lapisan, lapisan atas (fase air) dan lapisan bawah (fase 
kloroform) dan partisi dilakukan secara bertahap $(3 \times 12,5 \mathrm{~mL})$. Senyawa flavonoid diasumsikan berada pada lapisan bawah (fase organik), Fase organik kemudian dipekatkan dengan rotary evaporator. Ekstrak flavonoid dapat dihitung randemennya menggunakan rumus berikut:

$$
\% \text { Rendemen }=\frac{\text { Berat ekstrak }}{\text { Berat sampel }} \times 100
$$

\subsection{Penentuan Panjang Gelombang Maksimum}

Larutan DPPH 0,2 mM sebanyak $1,5 \mathrm{~mL}$ dimasukkan ke dalam tabung reaksi, ditambah 4,5 $\mathrm{mL}$ etanol p.a. kemudian diinkubasi pada suhu $37{ }^{\circ} \mathrm{C}$ dan didiamkan selama \pm 30 menit, dimasukkan ke dalam kuvet. Diamati $\lambda_{\text {maks }}$ larutan untuk digunakan pada tahap selanjutnya.

\subsection{Penentuan Waktu Kestabilan Pengukuran Antioksidan}

Dibuat larutan ekstrak 100 ppm sebanyak $25 \mathrm{~mL}$, kemudian diambil sebanyak 4,5 mL. Ditambahkan 0,2 mM larutan DPPH sebanyak $1,5 \mathrm{~mL}$, lalu diinkubasi pada suhu $37{ }^{\mathrm{O}} \mathrm{C}$. Larutan yang diperoleh dipipet ke dalam kuvet, kemudian dicari waktu kestabilan pada rentangan waktu 5-120 menit dengan interval 5 menit. Sampel diukur menggunakan spektronik 20+ pada $\lambda_{\text {maksyang telah diketahui pada tahap }}$ sebelumnya (Suroso, 2011).

\subsection{Pengukuran Potensi Antioksidan pada Sampel}

a. Absorbansi kontrol: 1,5 mL larutan DPPH dimasukkan ke dalam tabung reaksi, ditambahkan etanol p.a sebanyak 4,5 mL, kemudian ditutup tabung reaksi dengan aluminium foil, lalu diinkubasi pada suhu $37{ }^{\circ} \mathrm{C}$ selama waktu kestabilan yang telah didapatkan pada tahap sebelumnya, setelah itu larutan dimasukkan ke dalam kuvet hingga penuh dan diukur absorbansinya dengan $\lambda_{\text {maks }}$ yang didapatkan.

b. Sampel dilarutkan dalam etanol p.a dengan konsentrasi 10, 25, 50 dan 100 ppm. Tabung reaksi disiapkan untuk masing-masing konsentrasi, kemudian tiap-tiap tabung reaksi diisi dengan 4,5 $\mathrm{mL}$ ekstrak dan ditambahkan DPPH 1,5 mL (1:3). Perlakuan tersebut diulangi hingga tiga kali pada tiap konsentrasi. Sampel diinkubasi pada suhu $37^{\circ} \mathrm{C}$ kemudian diukur absorbansinya pada $\lambda$ maks. Data absorbansi yang diperoleh dari tiap konsentrasi masing-masing ekstrak dihitung nilai persen (\%) aktivitas antioksidannya (Rizkia, 2014):

$\%$ Aktivitas Antioksidan $=\frac{\text { Abs kontrol }- \text { Abs sampel }}{\text { Abs kontrol }} \times 100$ (2) Setelah didapatkan persen (\%) aktivitas antioksidan, selanjutnya masing-masing ekstrak dihitung nilai $\mathrm{IC}_{50}$ dengan memperoleh persamaan regresi menggunakan program "GraphPad prism5 software, Regression for analyzing dose-response data".

c. Pembanding vitamin $\mathrm{C}$ dilakukan seperti sampel, akan tetapi sampel diganti dengan larutan vitamin $\mathrm{C}$.

\subsection{Uji fitokimia flavonoid}

Ekstrak pekat masing-masing sampel dimasukkan dalam tabung reaksi kemudian dilarutkan dalam $1-2 \mathrm{~mL}$ metanol panas $50 \%$. Setelah itu ditambah logam $\mathrm{Mg}$ dan $0,5 \mathrm{~mL} \mathrm{HCl}$ pekat. Larutan berwarna merah atau jingga yang terbentuk, menunjukkan adanya flavonoid. Hasil uji pereaksi ini selanjutnya digunakan pada tahap pemisahan senyawa aktif dengan KLT analitik untuk mengidentifikasi golongan flavonoid. 


\subsection{Uji fitokimia Alkaloid}

Ekstrak pekat masing-masing sampel dimasukkan dalam tabung reaksi, ditambah $0,5 \mathrm{~mL} \mathrm{HCl} 2 \%$ dan larutan dibagi dalam dua tabung. Tabung I ditambahkan 3 tetes pereaksi Dragendorff, tabung II ditambahkan 3 tetes pereaksi Meyer. Jika tabung I terbentuk endapan jingga dan pada tabung II terbentuk endapan kekuning-kuningan atau putih, menunjukkan adanya alkaloid.

\subsection{Uji Fitokima Tanin}

Ekstrak pekat masing-masing sampel dimasukkan kedalam tabung reaksi, kemudian ditambahkan dengan 2-3 tetes larutan $\mathrm{FeCl}_{3} 1 \%$. Jika larutan menghasilkan warna hijau kehitaman menunjukkan adanya senyawa tanin.

\subsection{Uji Fitokima Saponin}

Ekstrak pekat masing-masing sampel dalam tabung reaksi ditambah air (1:1) sambil dikocok selama 1 menit, apabila menimbulkan busa ditambahkan 2 tetes $\mathrm{HCl} 1 \mathrm{~N}$ dan dibiarkan selama 10 menit, bila busa yang terbentuk bisa tetap stabil maka ekstrak positif mengandung saponin.

\subsection{Uji Fitokima Triterpenoid dan Steroid}

Ekstrak pekat masing-masing sampel dimasukkan dalam tabung reaksi, dilarutkan dalam 0,5 mL kloroform lalu ditambah dengan $0,5 \mathrm{~mL}$ asam asetat anhidrat. Campuran ini selanjutnya ditambah dengan $1-2 \mathrm{~mL} \mathrm{H}_{2} \mathrm{SO}_{4}$ pekat melalui dinding tabung tersebut. Jika hasil yang diperoleh berupa cincin kecoklatan atau violet pada perbatasan dua pelarut menunjukkan adanya triterpenoid, sedangkan jika terbentuk warna hijau kebiruan menunjukkan adanya steroid.

\subsection{Pemisahan Flavonoid}

Pemisahan dengan KLT Analitik menggunakan plat $\mathrm{G}_{60} \mathrm{~F}_{254} 1 \times 10 \mathrm{~cm}$ yang telah diaktifkan dengan pemanasanpada suhu $100{ }^{\circ} \mathrm{C}$ selama 30 menit. Ekstrak flavonoid ditotolkan pada jarak $1 \mathrm{~cm}$ dari tepi bawah plat dandikeringkan kemudian dielusi dengan jarak $8 \mathrm{~cm}$. Eluen yang digunakan adalah metanol-kloroform (1:39) dan (1:9), PE-etil asetat (5:1) dan kloroform-metanol-air $(9,7: 0,2: 0,1)$. Setelah gerakan larutan pengembang sampai pada garis batas, elusi dihentikan. Plat hasil elusi dikeringkan, noda yang terbentuk diamati dengan lampu UV pada gelombang maksimum $254 \mathrm{~nm}$ dan $366 \mathrm{~nm}$ dan dihitung nilai Rf. Eluen yang terbaik digunakan untuk pemisahan KLT preparatif.

$\mathrm{Rf}=\frac{\text { Jarak rambat senyawa }}{\text { Jarak rambat eluen dari penotolan }}$

Pemisahan dengan KLT preparatif sama dengan KLT Analitik, akan tetapi ukuran Platnya lebih besar yaitu $10 \mathrm{~cm}$ x $20 \mathrm{~cm}$ dan dielusi menggunakan eluen yang memberikan pemisahan terbaik pada KLT analitik. Isolat yang menunjukkan positif senyawa flavonoid dikerok. Isolat dilarutkan dalam etanol p.a dan disentrifuge untuk mengendapkan silikanya, kemudian disaring dan diambil filtratnya.

\subsection{Identifikasi Flavonoid menggunakan Spektrofotometer UV-Vis dan Pereaksi Geser}

Filtrat yang diperoleh dari hasil KLT preparatif dianalisis menggunakan spektrofotometer UV-Vis, masing-masing filtrat sebanyak $3 \mathrm{~mL}$ dimasukkan dalam kuvet dan diamati spektrumnya pada panjang gelombang $200-800 \mathrm{~nm}$. Identifikasi dilanjutkan dengan penambahan pereaksi geser $\mathrm{NaOH} 2 \mathrm{M}$, $\mathrm{AlCl}_{3} 5 \%, \mathrm{AlCl}_{3} 5 \% / \mathrm{HCl}, \mathrm{NaOAc}$, 
$\mathrm{NaOAc} / \mathrm{H}_{3} \mathrm{BO}_{3}$, kemudian diamati pergeseran puncak serapannya, tahapan kerja penggunaan pereaksi geser meliputi:

1. Isolat diamati pada panjang gelombang $200-800 \mathrm{~nm}$, dicatat spektrum yang dihasilkan.

2. Isolat dari tahap 1 ditambah dengan 3 tetes $\mathrm{NaOH} 2 \mathrm{M}$, dikocok hingga homogen dan diamati spektrum yang dihasilkan. Sampel didiamkan selama 5 menit dan diamati spektrum yang dihasilkan.

3. Isolat dari tahap 1ditambah 6 tetes pereaksi $\mathrm{AlCl}_{3} 5 \%$ dalam metanol, kemudian dicampur hingga homogen dan diamati spektrumnya. Sampel ditambah 3 tetes $\mathrm{HCl}$ kemudian dicampur hingga homogen dan diamati spektrumnya.

4. Isolat dari tahap 1 ditambah serbuk natrium asetat $\pm 250 \mathrm{mg}$. Campuran dikocok hingga homogen menggunakan vorteks dan diamati spektrumnya, selanjutnya larutan tersebut ditambah asam borat \pm 150 $\mathrm{mg}$, dikocok hingga homogen dan diamati spektrumnya.

\section{Hasil dan Pembahasan}

\subsection{Preparasi Sampel.}

Pengeringan dilakukan dengan cara diangin-anginkan pada suhu ruang, hal ini berfungsi mengurangi kadar air untuk menghindari tumbuhnya mikroba, sehingga sampel tidak mudah rusak. Pengeringan sampel pada suhu ruang berfungsi untuk menghindari rusaknya senyawa aktif yang terkandung dalam sampel. Menurt Hernawan, 2003 pengeringan sebaiknya dilakukan pada suhu kamar atau kurang dari $40{ }^{\circ} \mathrm{C}$, pada suhu lebih dari $40{ }^{\circ} \mathrm{C}$ dapat terjadi penurunan kadar dan ekstrabilitas flavonoid secara drastis. Tahap selanjutnya yakni penyerbukan sampel yang berfungsi untuk menyeragamkan ukuran sampel dengan ukuran 90 mesh dan memperluas permukaan, sehingga diharapkan proses ekstraksi lebih maksimal karena kontak antara sampel dengan pelarut lebih maksimal.

Proses ekstraksi serbuk rimpang kencur menggunakan metode maserasi. Prinsipnya adalah mengekstrak senyawa aktif yang dapat larut dalam pelarut berdasarkan tingkat kepolaran masingmasing pelarutnya like dissolves like (Khopkar, 2008). Metode ini didasarkan pada perendaman sampel didalam pelarut sehingga pelarut akan menembus dinding sel dan masuk ke dalam rongga sel yang mengandung senyawa aktif. Senyawa aktif akan larut dalam pelarut yang sesuai karena adanya perbedaan konsentrasi antara zat aktif di dalam sel dan di luar sel, sehingga larutan yang berdekatan terdesak keluar. Peristiwa tersebut akan berlangsung terusmenerus sampai terjadi keseimbangan konsentrasi antara larutan yang di luar dengan yang ada di dalam sel (Voight, 1995).

Pemilihan pelarut etanol $80 \%$ karena memiliki nilai kepolaran yang lebih tinggi daripada etanol p.a sehingga dapat mengekstrak sampel dengan lebih maksimak. Selain itu, karena sifat ketoksikan yang rendah daripada pelarut alkohol lainnya (Guenther, 2006).

Filtrat hasil maserasi di rotary vacuum evaporator yaitu proses pemisahan ekstrak dari pelarut dengan pemanasan yang diatur dengan mempercepat putaran dari labu alas bulat . Pelarut dapat menguap pada suhu $5-10{ }^{\circ} \mathrm{C}$ dibawah titik didihnya karena adanya penurunan tekanan (Sudjaji, 1988). Ekstrak pekat yang dihasilkan sebanyak 5 gram dengan warna hijau pekat. Selanjutnya, dihidrolisis menggunakan $\mathrm{HCl}$ $2 \mathrm{~N}$ untuk mempercepat pemutusan ikatan glikosida antara senyawa glikon (gula) dan aglikon (bukan gula).

Hasil partisi menghasilkan 2 lapisan yaitu lapisan air dan lapisan organik. Komponen 
glikon terdistribusi pada fase air sedangkan senyawa metabolit sekunder (aglikon) terdistribusi pada fase organik. Flavonoid terkandung dalam fasa organik karena memiliki kepolaran yang sesuai. senyawasenyawa yang memiliki kepolaran berbeda dapat terekstrak kedalam pelarut yang sesuai (Voight, 1994). Fasa organik dipekatkan menggunakan vacuum rotary evaporator untuk menghilangkan pelarutnya sehingga diperoleh ekstrak flavonoid.

\subsection{Penentuan Panjang Gelombang Maksimum}

Panjang gelombang maksimal DPPH 0,2 $\mathrm{mM}$ adalah $515,1 \mathrm{~nm}$.

\subsection{Penentuan Waktu Kestabilan Pengukuran Antioksidan}

Penentuan waktu kestabilan berfungsi mengetahui waktu yang dibutuhkan sampel untuk mereduksi radikal DPPH dengan sempurna dan memiliki absorbansi yang stabil.

Tabel 1. Waktu kestabilan sampel

\begin{tabular}{cc}
\hline Sampel & $\begin{array}{c}\text { Waktu kestabilan } \\
\text { (menit) }\end{array}$ \\
\hline Ekstrak etanol 80\% & $60-70$ \\
Fraksi kloroform & $75-85$ \\
Vitamin C & $50-60$ \\
\hline
\end{tabular}

Masing-masing sampel diinkubasi pada suhu $37{ }^{\circ} \mathrm{C}$ selama pengukuran waktu kestabilan. Pada suhu ini reaksi berlangsung lebih cepat dan optimal. Suroso (2007) membandingkan pengukuran waktu kestabilan DPPH dari sampel yang diinkubasi dengan suhu ruang dan pada suhu $37{ }^{\circ} \mathrm{C}$ didapatkan hasil bahwa pada suhu $37{ }^{\circ} \mathrm{C}$ reaksi DPPH dengan sampel lebih stabil yang ditandai dengan nilai absorbansi yang tidak jauh berbeda pada menit ke 30-55.

\subsection{Uji Aktivitas Antioksidan}

Pengujian aktivitas antioksidan pada sampel dilakukan pada panjang gelombang $515.1 \mathrm{~nm}$ selama waktu kestabilan sebagaimana DPPH berperan sebagai radikal bebas akan bereaksi dengan antioksidan membentuk DPPH-H (1,1difenil-2-pikrilhidrazin). Antioksidan akan mendonorkan atom hidrogennya kepada radikal DPPH untuk menetralkan radikal DPPH dan membentuk radikal antioksidan yang lebih stabil.

\section{$\mathrm{DPPH}^{*}+\mathrm{AH} \longrightarrow \mathrm{DPPH}-\mathrm{H}+\mathrm{A}^{*}$}

Larutan kontrol berfungsi untuk mengetahui absorbansi radikal DPPH sebelum direduksi oleh sampel. Selisih absorbansi sampel yang telah direduksi DPPH dengan absorbansi kontrol merupakan sisa radikal DPPH yang terbaca pada spektrofotometer UV-Vis. Semakin besar selisihnya semakin besar aktivitas antioksidan sampel.

Tabel 2. Persentase aktivitas antioksidan

\begin{tabular}{cccc}
\hline $\begin{array}{c}\text { Konsentrasi } \\
\text { sampel } \\
\text { (ppm) }\end{array}$ & \multicolumn{3}{c}{$\%$ Aktivitas antioksidan } \\
Ekstrak & $\begin{array}{c}\text { Fraksi } \\
\text { etanol } \\
\text { klorofor } \\
80 \%\end{array}$ & $\begin{array}{c}\text { Vitamin } \\
\text { m }\end{array}$ \\
\hline 10 & 49 & 33 & 95 \\
25 & 53,53 & 39,2 & 96 \\
50 & 57,78 & 42,5 & 97 \\
75 & 60,19 & 47,8 & 97 \\
100 & 64,93 & 54,9 & 97 \\
\hline
\end{tabular}

Persen (\%) aktivitas antioksidan merupakan salah satu parameter yang menunjukkan kemampuan suatu antioksidan dalam menghambat radikal bebas. Semakin tinggi persen (\%) aktivitas antioksidan menunjukkan banyaknya atom hidrogen yang diberikan oleh senyawa aktif kepada radikal DPPH sehingga DPPH tereduksi menjadi DPPH-H (Rahayu dkk, 2010). 
Persentase aktivitas antioksidan tertinggi terdapat pada vitamin $\mathrm{C}$ diikuti ekstrak etanol $80 \%$, dan ekstrak fraksi kloroform. Pada ekstrak etanol $80 \%$ selain mengandung senyawa flavonoid juga terdapat senyawa alkaloid dan tannin yang bersifat sinergis sehingga, persen aktivitasnya lebih besar dibandingkan fraksi kloroform.

Parameter lain yang digunakan untuk mengetahui kekuatan antioksidan ialah $\mathrm{IC}_{50}$ (Inhibition Concentration 50 Value). $\mathrm{IC}_{50}$ merupakan konsentrasi substrat yang dapat menyebabkan berkurangnya $50 \%$ aktivitas DPPH (Molyneux, 2003).

Tabe 3. Nilai $\mathrm{IC}_{50}$ sampel

\begin{tabular}{cc}
\hline Sampel & Nilai $\mathrm{IC}_{50}(\boldsymbol{\mu g} / \mathrm{mL})$ \\
\hline Ekstrak etanol $80 \%$ & 13,07 \\
Fraksi kloroform & 81,09 \\
Vitamin C & 0,04 \\
\hline
\end{tabular}

Semakin kecil nilai $\mathrm{IC}_{50}$ menandakan semakin besar aktivitas antioksidan sehingga konsentrasi yang dibutuhkan untuk meredam radikal DPPH sebesar $50 \%$ semakin kecil. Vitamin C memiliki aktivitas antioksidan tertinggi, kemudian diikuti ekstrak etanol $80 \%$ dan ekstrak fraksi kloroform. Hal ini disebabkan oleh kestabilan struktur vitamin $\mathrm{C}$ yang dapat mendonorkan dua atom hidrogennya. Vitamin $\mathrm{C}$ dan ekstrak etanol $80 \%$ memiliki nilai $\mathrm{IC}_{50}<50 \mathrm{ppm}$ dan termasuk dalam kategori sangat kuat aktivitasnya, sedangkan nilai $\mathrm{IC}_{50}$ ekstrak fraksi kloroform berada dalam rentang 50100 ppm, hal ini menunjukkan bahwa ekstrak fraksi kloroform memiliki aktivitas antioksidan yang kuat.
Kuatnya aktivitas antioksidan ekstrak etanol $80 \%$ bisa dipengaruhi oleh kestabilan struktur dan posisi gugus hidroksil pada ketiga senyawa yang terdapat pada ekstrak etanol $80 \%$. Menurut Winarno, 2008 posisi orto gugus $\mathrm{OH}$ pada suatu senyawa merupakan posisi yang paling bagus untuk antioksidan. Flavonoid mendonorkan atom $\mathrm{H}$ sebagai peredam radikal DPPH, sehingga terjadi penstabilan radikal flavonoid dengan adanya resonansi.

\subsection{Uji Fitokimia dengan Reagen}

Uji kualitatif untuk mengetahui senyawa aktif yang terkandung dalam tanaman. Adanya reaksi pengujian warna dengan suatu reaksi warna (Kristanti, 2008). Uji fitokimia reagen dilakukan pada ekstrak etanol $80 \%$ rimpang kencur dan ekstrak pekat hasil partisi yaitu fraksi kloroform. Berikut ini hasil pengujian fitokimia reagen dapat dilihat pada Tabel 4:

Tabel 4. Hasil uji fitokimia rimpang kencur

\begin{tabular}{|c|c|c|c|}
\hline \multirow{2}{*}{$\begin{array}{l}\text { Golongan } \\
\text { senyawa aktif }\end{array}$} & \multicolumn{2}{|c|}{ Ekstrak } & \multirow{2}{*}{$\begin{array}{l}\text { Keterangan } \\
\text { Hasil Positif }\end{array}$} \\
\hline & $\begin{array}{c}\text { Etanol } \\
80 \%\end{array}$ & $\begin{array}{c}\text { Fraksi } \\
\text { kloroform }\end{array}$ & \\
\hline Flavonoid & + & + & $\begin{array}{c}\text { Berwarna } \\
\text { jingga }\end{array}$ \\
\hline $\begin{array}{l}\text { Alkaloid } \\
\text { Mayer }\end{array}$ & + & - & $\begin{array}{c}\text { Endapan } \\
\text { jingga }\end{array}$ \\
\hline Dragendroff & + & - & $\begin{array}{l}\text { Endapan } \\
\text { kuning }\end{array}$ \\
\hline Tanin & + & - & $\begin{array}{c}\text { Berwarna } \\
\text { hijau } \\
\text { kehitaman }\end{array}$ \\
\hline Saponin & - & - & $\begin{array}{l}\text { Tidak ada } \\
\text { busa atau } \\
\text { gelembung }\end{array}$ \\
\hline Triterpenoid & - & - & $\begin{array}{c}\text { Tidak } \\
\text { terbentuk } \\
\text { cincin } \\
\text { coklat }\end{array}$ \\
\hline ingan: & $\begin{array}{l}=\text { Posi } \\
=\text { Tida }\end{array}$ & $\begin{array}{l}\text { ngandung } \\
\text { andung se }\end{array}$ & $\begin{array}{l}\text { awa } \\
\text { va }\end{array}$ \\
\hline
\end{tabular}

Hasil uji fitokimia dengan reagen menunjukkan bahwa pada ekstrak etanol 
$80 \%$ dan fraksi kloroform positif mengandung senyawa flavonoid yang ditandai dengan adanya warna jingga.

Selain itu, pada ekstrak etanol 80\% positif mengandung senyawa alkaloid yang ditandai dengan terjadi perubahan warna ekstrak dari kuning kehijauan menjadi oranye dengan endapan jingga setelah diberi pereaksi Dragendorf, sedangkan pada uji Mayer didapatkan endapan kekuningankuningan. Positif mengandung tannin yang ditandai dengan terbentuknya warna hijau kehitaman pada ekstrak setelah ditambahkan dengan $\mathrm{FeCl}_{3}$ disebabkan karena tanin akan membentuk senyawa kompleks dengan ion $\mathrm{Fe}^{3+}$ (Effendy, 2007).

\subsection{Pemisahan senyawa flavonoid dengan KLT analitik}

KLT analitik ini digunakan untuk mencari eluen terbaik dari beberapa eluen yang baik dalam pemisahan senyawa flavonoid. Eluen yang baik adalah eluen yang menghasilkan senyawa dalam jumlah yang banyak ditandai dengan munculnya noda. Noda yang terbentuk tidak berekor dan jarak antara noda satu dengan yang lainnya jelas (Harborne, 1987).

KLT yang digunakan terbuat dari silika dengan ukuran $1 \times 10 \mathrm{~cm} \mathrm{G}_{60} \mathrm{~F}_{254}$ (Merck). Pemisahan KLT akan optimal jika ukuran bercak penotolan dibuat sekecil mungkin. Penotolan sampel yang tidak tepat akan menyebabkan noda yang menyebar dan puncak ganda (Gandjar, 2007).

Tabel 5. Pemisahan flavonoid dengan KLTA

\begin{tabular}{clc}
\hline No. & \multicolumn{1}{c}{ Eluen } & Jumlah noda \\
\hline 1. & $\begin{array}{l}\text { PE:etil asetat (5:1) } \\
\text { PE:etil asetat } \\
(19: 1)\end{array}$ & 7 \\
3. & $\begin{array}{l}\text { PE:kloroform } \\
(1: 9)\end{array}$ & 5 \\
4. & $\begin{array}{l}\text { Metanol:kloroform } \\
(1: 19)\end{array}$ & 1 \\
\hline
\end{tabular}

Tabel 5 menunjukkan variasi pelarut PE: etil aseta (5:1) merupakan eluen terbaik yang mampu memberikan pemisahan terbaik dibandingkan dengan eluen lainnya. Eluen ini mampu memisah 7 noda dan menunjukkan adanya flavonoid setelah diamati bawah lampu UV 254 dan $366 \mathrm{~nm}$ dengan pereaksi $\mathrm{FeCl}_{3} 2 \%$. Nilai Rf masing-masing noda pada eluen terbaik ini adalah $0,06,0,19,0,6,0,7,0,85,0,91$ dan 0,96 . Rf yang lebih besar menunjukkan senyawa cenderung lebih terdistribusi pada fase geraknya (PE:etil asetat) yang bersifat kurang. Sehingga, proses migrasi solut berlangsung lebih cepat.

\subsection{Pemisahan Senyawa Tanin dengan KLT Preparatif}

Eluen yang digunakan merupakan eluen terbaik pada pemisahan KLTA yaitu PE:etil asetat (5:1).

Pemisahan flavonoid menggunakan KLTP menghasilkan 8 spot. Perbedaan jumlah noda pada pemisahan KLTA dan KLTP dimungkinkan karena pemisahan senyawa pada KLTA kurang maksimal dilihat dari ukuran plat pada KLTA yaitu $1 \times 10$ sedangkan pada KLTP 10x20 dan prosen penjenuhan dari keduanya sehingga, proses elusinya lebih maksimal pada KLTP.

\subsection{Identifikasi senyawa flavonoid dengan spektrofotometer UV-Vis dan pereaksi geser}

Spektrofotometer UV-Vis merupakan metode yang berguna untuk menganalisis dugaan awal struktur flavonoid. Metode ini membantu mengidentifikasi jenis senyawa polifenol dan pola oksigenasinya. Kedudukan gugus hidroksi fenol pada inti flavonoid dapat ditentukan dengan menambahkan pereaksi geser (Markham, 1988). Serapan khas senyawa flavonoid pada UV-Vis mempunyai dua pita. Panjang gelombang pada pita I antara $300-550 \mathrm{~nm}$, 
Sedangkan pada pita II mempunyai panjang gelombang antara $210-285 \mathrm{~nm}$. Isolat hasil KLTP yang diidentifikasi pada penelitian ini adalah isolat 6,7 dan 8 dan dilarutkan dalam etanol.
Tabel 6. Hasil pemisahan dengan KLTP

\begin{tabular}{cccc}
\hline Spot & $\begin{array}{c}\text { Nilai } \\
\text { Rf }\end{array}$ & $\begin{array}{c}\text { Warna noda } \\
\text { dibawah sinar } \\
\mathbf{U V}_{\mathbf{3 6 6}} \mathbf{n m}\end{array}$ & $\begin{array}{c}\text { Dugaan } \\
\text { senyawa }\end{array}$ \\
\hline 1 & 0,19 & Kuning & - \\
2 & 0,24 & Hijau & Flavonoid \\
3 & 0,39 & Merah muda & - \\
4 & 0,53 & Kuning & - \\
5 & 0,58 & Merah muda & - \\
6 & 0,69 & Oranye & Flavonoid \\
7 & 0,72 & Hijau & Flavonoid \\
\hline
\end{tabular}

Tabel 7. Data spektrum isolat 6, 7 dan 8

\begin{tabular}{cccccccc}
\hline \multirow{2}{*}{ Isolat } & \multicolumn{6}{c}{ Panjang gelombang maksimum (nm) dengan penambahan pereaksi geser } \\
\cline { 2 - 8 } & $\mathrm{EtOH}$ & $\begin{array}{c}\mathrm{EtOH}+ \\
\mathrm{NaOH}\end{array}$ & $\begin{array}{c}\mathrm{EtOH}+ \\
\mathrm{NaOH} 5 \text { menit }\end{array}$ & $\begin{array}{c}\mathrm{EtOH}+ \\
\mathrm{AlCl}_{3}\end{array}$ & $\begin{array}{c}\mathrm{EtOH}+ \\
\mathrm{AlCl}_{3} / \mathrm{HCl}\end{array}$ & $\begin{array}{c}\mathrm{EtOH}+ \\
\mathrm{NaOAc}\end{array}$ & $\begin{array}{c}\mathrm{EtOH}+ \\
\mathrm{NaOAc}_{3} \mathrm{BO}_{3}\end{array}$ \\
\hline 6 & 291,1 & 285,0 & 289,0 & 292,9 & 292,0 & 291,1 & 284,9 \\
7 & 308,0 & 307,0 & 308,0 & 308,0 & 309,1 & 307,0 & 302,0 \\
& 217,7 & 216,0 & 219,0 & - & - & 217,0 & 220,0 \\
8 & 280,0 & 280,1 & 281,8 & 281,8 & 282,6 & 280,0 & 282,9 \\
\hline
\end{tabular}

Dari data spektrum di atas diasumsikan senyawa flavonoid yang mungkin dari hasil KLT preparatif dibawah sinar UV $366 \mathrm{~nm}$ adalah isolat 7. Hal ini dikarenakan isolat 7 tersebut setelah ditambahkan pereaksi geser memiliki 2 panjang gelombang maksimum pada daerah $210-285 \mathrm{~nm}$ (pita II) dan 300 - $550 \mathrm{~nm}$ (pita I).

Isolat yang lain diduga bukan merupakan senyawa flavonoid karena setelah ditambahkan pereaksi geser ada yang memiliki satu panjang gelombang maksimum dan panjang gelombang maksimum pada pita I dan pita II tidak sesuai dengan data literatur. Sehingga diperkirakan isolat-isolat tersebut dimungkinkan merupakan senyawa polifenol yang lain.

Penambahan pereaksi geser $\mathrm{NaOH}$ menyebabkan terjadinya pergeseran batokromik sebesar 1,5 pada pita II, yang menunjukkan adanya gugus hidroksi pada cincin A yaitu pada atom C-7. Dugaan ini diperkuat dengan pergeseran batokromik pada pita II, setelah penambahan pereaksi geser $\mathrm{NaOAc}$ pada isolat.

Penambahan pereaksi geser $\mathrm{NaOH}$ setelah 5 menit menunjukkan adanya pergeseran hipsokromik pada pita II, hal ini menunjukkan bahwa ada gugus orto dihidroksi pada cincin A. Hal ini diperkuat dengan adanya pergeseran hipsokromik pada pita II setelah penambahan pereaksi geser $\mathrm{H}_{3} \mathrm{BO}_{3}$, yang menunjukkan adanya gugus orto dihidroksi pada atom C-6,C-7 atau C-7,C-8.

Penambahan $\mathrm{AlCl}_{3} \quad$ tidak meyebabkan pergeseran panjang gelombang, hal ini menunjukkan bahwa 5$\mathrm{OH}$ dengan gugus prenil pada cincin 6 . Sedangkan, penambahan $\mathrm{AlCl}_{3} / \mathrm{HCl}$ menghasilkan pergeseran batokromik pada pita I sebesar $1,1 \mathrm{~nm}$ yang memungkinkan adanya gugus o-diOH pada cincin B dari auron dan khalkon.

Pergeseran batokromik yang terjadi pada penambahan pereaksi geser $\mathrm{NaAc}$ 
menujukkan adanya gugus $7-\mathrm{OH}$ atau ada gugus yang peka terhadap basa seperti pada C-6,C-7 atau C-7,C-8 atau C-3,C-4'dihidroksi. Pergeseran hipsokromik yang terjadi pada pita I dan pita II, setelah penambahan pereaksi geser $\mathrm{NaAc}$ dan $\mathrm{H}_{3} \mathrm{BO}_{3}$ menunjukkan adanya gugus orto dihidroksi pada cincin A dan B pada atom C-6,C-7 atau C-7,C-8. Berdasarkan data interpretasi perubahan panjang gelombang maksimum isolat 7 dari spektrofotometer UV-Vis maka senyawa flavonoid yang mungkin dari isolat 7 termasuk golongan flavanon atau dihidroflavonol, karena spektrum yang terbentuk merupakan ciri khas dari flavanon atau dihidroflavonol dengan kemungkinan terdapat gugus hidroksi pada C-3,C-6, C-7, dan C-4'.

\section{Kesimpulan}

Ektrak etanol rimpang kencur $80 \%$ dan fraksi kloroform memiliki potensi antioksidan yang kuat dengan nilai persen aktivitas tertinggi 64,93 \% dan 54,9\% dengan nilai $\mathrm{IC}_{50} 13,07 \mu \mathrm{g} / \mathrm{mL}$ dan 81,9 $\mu \mathrm{g} / \mathrm{mL}$. Hasil dari KLTA eluen terbaik adalah PE:etil asetat yang mampu menghasilkan spot sebanyak 7. Dan hasil KLTP menghasilkan 8 spot. Hasil identifikasi menggunakan spektrofotometer UV-Vis dan diperkuat dengan penambahan pereaksi geser menunjukkan bahwa isolat 7 merupakan golongan flavanon atau dihidroflavonol.

\section{Ucapan Terima Kasih}

1. DIPA UIN Malang atas bantuan pendanaan penelitian

2. Rachmawati Ningsih, M.Si selaku dosen konsultan.

3. Semua staf laboratorium jurusan kimia yang telah membatu dalam melayani fasilitas alat dalam proses penelitian.

\section{Daftar Pustaka}

Cuppett, S.M., dan Schrepf, C. Hall III. 1954. Natural Antioxidant Are They Reality. Dalam Foreidoon Shahidi: Natural Antioxidants, Chemistry, Health Effect and Applications, AOCS Press, Champaign, Illinois: 1224.

Effendy. 2007. Perspektif Baru Kimia Koordinasi Jilid I. Malang: Banyu Media Publishing.

Fitriyani, A., Winarti, L., Muslichah, S. dan Nuri. 2011. Uji Antiinflamasi Ekstrak Metanol Daun Sirih Merah (Piper crocatum ruiz \&Pav ) pada Tikus Putih. Majalah Obat Tradisional: 16 (1), 34-42.

Gandjar, I.G dan Rohman, A. 2007. Kimia Farmasi Analisis. Yogyakarta: Pustaka Pelajar.

Gholib, D. 2009. Daya hambat ekstrak kencur terhadap pertumbuhan jamur Tripchophyton mentagrobhytes dan cryptococcus neoformans jamur penyebab penyakit kurap pada kulit dan penyakit paru, Bul. Littro, vol.20, no.1, hal 59-67.

Guenther, E. 2006. Minyak Atsiri. Jakarta : UI Press.

Harborne, J. 1987. Metode Fitokimia: Penuntun Cara Modern Menganalisis Tumbuhan. Cetakan Kedua. Penerjemah: Padmawinata, K. dan I. Soediro. Bandung: ITB.

Hasanah, A. N., Nazaruddin, F., Febrina, E., dan Zuhrotun, A. (2011). Analisis Kandungan Minyak Atsiri dan Uji Aktivitas Antiinflamasi Ekstrak Rimpang Kencur (Kaempferia galanga L.) . Jurnal Matematika \& Sains. 147-153.

Khopkar. 2008. Konsep Dasar Kimia Analisis. Jakarta: Universitas Indonesia.

Markham, K.R. 1998. Cara Mengidentifikasi Flavonoid, 
Terjemahan Kosasih Padmawinata. Bandung: Penerbit ITB.

Marliana, E. 2005. Aktivitas Antioksidan Ekstrak Etanol Daun Andong (Cordyline fruticosa L.). Jurnal Mulawarman Scientifie, Volume 11, Nomor 1, April 2012 ISSN 1412498X.

Milyasari, C. 2011. Isolasi Senyawa Antibakteri Staphylococcus aureus dan E.coli dari Ekstrak Buah Blimbing Wuluh (Averrhoa blimbi. L). Skripsi Tidak Diterbitkan. Malang: Fakultas Sains dan Teknologi Universitas Islam Negeri Malang.

Molyneux, P. 2003. The Use of The Stable Free Radical Diphenylpicrylhydrazyl (DPPH), for Estimating Antioxidant Activity. Journal of Science and Technology. Institute of Food Research Colney, Norwich, United Kingdom. Vol 26(2) : 211-219.
Rahayu, D dan Hastuti, S.D. 2009. Stabilitas Saponin sebagai Antibiotik Alami Hasil Isolasi Gel Daun Aloe barbandis miller pada Variasi Suhu dan Lama Simpan. Jurnal. Malang: Jurusan Peternakan Fakultas Peternakan-Perikanan Universitas Muhammadiyah Malang.

Suroso, H.C. 2007. Uji Antioksidan dan Identifikasi Senyawa Aktif pada Tanaman Anting-anting (Achalypha Indica L.). Skripsi Tidak Diterbitkan. Malang: Jurusan Kimia Fakultas Sains dan Teknologi Universitas Islam Negeri Maaulana Malik Ibrahim Malang.

Voight, R.1995. Buku Pelajaran Teknologi Farmasi. Diterjemahkan oleh Soedani Noerono Soewandi, Apt. Yogyakarta: Universitas Gajah Mada press

Wijayakusuma, H. 2008. Pengobatan Herbal dengan Ramuan Tionghoa. Jakarta: Niaga Swadaya. 